\title{
Aves del Santuario Nacional Tabaconas Namballe, vertiente oriental de los Andes del Norte Peruano
}

\author{
Birds of the National Sanctuary Tabaconas Namballe, eastern slope of the Peruvian Northern \\ Andes
}

\section{Sonia Salazar ${ }^{1}$ y José Luis Mena ${ }^{2,3}$}

\author{
1 Universidad Nacional Mayor de San Marcos, Av. Venezuela s/n, Lima, Perú. \\ 2 World Wildlife Fund - Peru, Trinidad Morán 853, Lince, Lima, Perú. \\ 3 Museo de Historia Natural "Vera Alleman Haeghebaert", Universidad Ricardo Palma, Apartado postal 1801, A. Benavides 544-Santiago de Surco, Lima \\ 33, Perú. \\ E-mail Sonia Salazar: sonia.marite@gmail.com \\ E-mail José Luis Mena: menaa.jl@gmail.com
}

\begin{abstract}
Resumen
El Santuario Nacional Tabaconas Namballe (SNTN) se encuentra en el límite de distribución de muchas especies endémicas de los Andes del Norte, en un área amenazada por la deforestación y con muchos vacíos de información ornitológica. Reportamos una lista actualizada de la diversidad de aves del Santuario, así como de sus especies de interés de conservación. Para lo cual se evaluaron tres localidades representativas: Páramos, Chichilapa y El Sauce, durante la época seca (setiembre, octubre - 2014) y de lluvia (marzo, abril - 2015). Se aplicaron varios métodos complementarios: puntos de conteo, capturas con redes de niebla, transectos nocturnos y registros asistemáticos. Se registró 197 (40 familias) y 153 (39 familias) especies en época seca y de lluvia respectivamente, con un total de 226 especies y 42 familias. Para el listado final se incluyeron registros de un promedio de 45 cámaras trampa, operativas desde agosto 2014 hasta abril 2015, más registros concluyentes de evaluaciones ornitológicas previas. Este trabajo reporta 82 nuevos registros de aves para el Santuario, 7 de los cuales provienen de cámaras trampa. En este sentido, la diversidad total de aves del Santuario es 290 especies y 46 familias. Aparte de las 45 especies entre endémicos, amenazados y casi amenazados de extinción, se destaca el nuevo registro para la región Cajamarca la Perdiz Gris Tinamus tao. Los resultados encontrados sugieren que aún falta mucho por conocer sobre la diversidad de aves del Santuario; sin embargo, resalta el rol clave del área protegida para la conservación de aves de esta región.
\end{abstract}

Palabras clave: aves; SNTN; Cajamarca; endemismo; Andes del Norte.

\section{Abstract}

The Tabaconas Namballe National Sanctuary (TNNS) is located at the limit of distribution of many endemic species from the Northern Andes, in an area threatened by deforestation and with many gaps in ornithological information. We report an updated list of species of the Sanctuary, and identify those species of conservation concern. We sampled three representative sites: Páramos, Chichilapa and El Sauce, during the dry season (September - October in 2014) and rainy season (March - April in 2015). We employed several complementary methods: counting points, mist-nets, nocturnal transects and non-systematic records. We recorded 197 (40 families) and 153 (39 families) species in the dry and rainy seasons respectively, with a total of 226 species and 42 families. In order to get an updated checklist, we include records of an average of 45 trap cameras, operative from August 2014 to April 2015, and we compile conclusive records from previous ornithological assessments. This work reports 82 new records of birds of the Sanctuary, 7 of which come from camera traps. In this way, the bird diversity of the Sanctuary is 290 species and 46 families. In addition to the 45 species between endemic, threatened and near threatened with extinction, we highlight a new record from the region Cajamarca, the Gray Tinamou Tinamus tao. Our results suggest that there is still much to know about the diversity of birds in the Sanctuary, however, it highlights the key role of this protected area in terms of bird conservation in this region.

Keywords: birds; TNNS; Cajamarca; endemism; Northern Andes.

Citación:

Salazar S. y J.L. Mena. 2018. Aves del Santuario Nacional Tabaconas Namballe, vertiente oriental de los Andes del Norte Peruano. Revista peruana de biología 25(2): 091 - 110 (Mayo 2018). doi: http://dx.doi. org/10.15381/rpb.v25i2.14686

$\begin{array}{ll}\text { Presentado: } & 16 / 11 / 2017 \\ \text { Aceptado: } & \text { 28/03/2018 } \\ \text { Publicado online: } & \mathbf{3 0 / 0 5 / 2 0 1 8}\end{array}$

Fuentes de financiamiento: El presente trabajo se realizó gracias al financiamiento del proyecto Soluciones Naturales al Cambio Climático liderado por World Wildlife Fund-Perú.

Información sobre los autores: SS y JLM elaboraron y diseñaron el estudio. SS realizó el trabajo de campo y escribió el manuscrito. JLM contribuyó al manuscrito y elaboró el mapa.

Los autores no incurren en conflictos de intereses. 


\section{Introducción}

El Santuario Nacional Tabaconas Namballe (SNTN) es reconocido en el mundo como una de las áreas importantes para la conservación de las aves (Birdlife International 2017a), bajo él IBA 51 (Important Bird Area 51). Consecuentemente, cuenta con una gran diversidad de aves, entre ellas especies globalmente amenazadas de extinción y endémicas de distribución restringida. El Santuario se ubica cerca al límite sur de los Andes del Norte (NAN) y de la frontera con Ecuador (Parker et al. 1985, INRENA 2007). Esta ubicación le confiere un alto potencial para el registro de nuevas especies al país; así como, la de especies endémicas de distribución restringida o pertenecientes a EBAs (Statterfield et al. 1998, Birdlife International 2017a), ya que en el confluyen tres Áreas de Endemismo de Aves (EBAs): el Central Andean páramo (EBA 043), Ecuador-Peru East Andes (EBA 044) y Southern Central Andes (EBA 046). Evaluaciones ornitológicas en áreas cercanas al Santuario, indican que su avifauna se encuentra más emparentada con la de Ecuador y Colombia que con la avifauna del sur de la depresión de Huancabamba (Andes Centrales). De hecho, presenta un alto grado de endemismo, que caracteriza el norte de la depresión de Huancabamba, entre endémicos del NAN compartidos con Ecuador y Colombia (Parker et al. 1985, CDC 1992). En Perú el Santuario es la única Área Natural Protegida que resguarda la extraordinaria biodiversidad del NAN, defendiendo un área estrecha presionada por el avance contundente de la colonización, la deforestación y la ampliación de la frontera agrícola (Salazar et al. 2017).

En el Santuario se han realizado tres evaluaciones rápidas de su avifauna (Amanzo et al. 2003, Barrio 2006, Zeballos 2010); de las cuales excluyendo registros no concluyentes (entrevista a pobladores locales, especies posibles divagantes, o no identificadas "sp."), han llegado a registrar un total de 208 especies dentro del Santuario. La primera evaluación (Amanzo et al. 2003) contempló localidades dentro y fuera (zona de amortiguamiento) del Santuario, registrándose 137 (Páramos y El Sauce) y 61 (Alto Samaniego) especies respectivamente. Los hábitats evaluados en aquella ocasión fueron páramo y bosque montano, abarcando también zonas antrópicas. La segunda evaluación fue en los páramos, donde Barrio (2006) registró 36 especies. La tercera abarcó zonas de páramo y bosque montano, registrando un total de 131 especies (Zeballos 2010). Estas evaluaciones y las realizadas en áreas circundantes indican que el conocimiento de la diversidad ornitológica del Santuario aún es incompleto. Asumiendo que cuenta con la misma riqueza del adyacente y extensamente estudiado Cerro Chinguela (273 especies), quedarían por registrar al menos $20 \%$ de sus especies, incluyendo varias endémicas. En este trabajo reportamos una lista actualizada de la diversidad de aves y especies de interés de conservación del Santuario, a partir de un estudio que incluyó evaluaciones en la época seca y de lluvia; a la que sumamos registros de cámaras trampa y registros obtenidos en evaluaciones previas.

\section{Materiales y métodos}

Área de estudio.- El SNTN se encuentra en la vertiente oriental de la cordillera occidental de los Andes del Norte de Perú, específicamente en la región Cajamarca, provincia de San Ignacio abarcando los distritos Tabaconas y Namballe. Comprende 31636.98 ha y su altitud va de ca 1600 a $3800 \mathrm{~m}$. Los principales hábitats en el Santuario son las lagunas arrebiatadas, páramos, bosques montanos húmedos y vegetación secundaria; existiendo además áreas antrópicas. Según su accesibilidad se eligieron tres localidades de evaluación: El Sauce, Chichilapa y los Paramos.

El Sauce (Namballe, 1600 - 2400 m) está ubicado al lado este del Santuario. Se puede acceder desde San Ignacio vía tres horas en carretera afirmada - trocha carrozable hacia el caserío Miraflores. Luego cuatro horas en camino de herradura hacia el caserío El Sauce, y finalmente dos horas de camino hasta llegar dentro del Santuario. La zona de vida es Bosque húmedo - Premontano Tropical (Holdridge 1967, INRENA 2007); las áreas evaluadas comprendieron zonas agropecuarias, bosques secundarios y bosque húmedo de montaña. Entre la vegetación se encuentran árboles dispersos de Podocarpus sp., Weinmannia sp., Miconia sp., helechos, heliconias, plantas epífitas y parches de chusquea entre otros.

Chichilapa (Tabaconas 2000 - 2700 m) está ubicado al sur del Santuario. Se accede desde el pueblo de Tabaconas a dos horas de camino. La zona de vida es Bosque muy húmedo - Montano Bajo Tropical (Holdridge 1967, INRENA 2007). Parte de esta localidad es zona de recuperación antrópica. El bosque presenta una mayor densidad de helechos y plantas epífitas, algunas plantas presentes son Fabaceas, Melastomatáceas, Weinmannia sp., además de parches de chusquea y árboles de Podocarpus sp.

Los Páramos (Tabaconas, 3100 - 3700 m) están ubicados a siete horas de camino desde la Estación Biológica Chichilapa. La zona de vida es Bosque Pluvio Montano Tropical (Holdridge 1967, INRENA 2007). La vegetación dominante es el pajonal húmedo, rodeada por matorrales y bosques enanos en sus límites. Entre las plantas se encuentran Neurolepis aristata (Poacea), Festuca sp., Senecio sp., Escallonia sp., Clusia sp., Weinmannia sp., Hesperomeles sp., Brachyotum sp. y Aethantus sp., entre otros.

Estudio de campo.- Se realizó una evaluación en época seca (setiembre - octubre en 2014) y otra en época de lluvia (marzo - abril en 2015). Por época, cada localidad fue evaluada durante ocho a nueve días. Por día se evaluó un transecto diferente de alrededor $1.5 \mathrm{~km}$, donde se realizaron 10 censos por puntos de conteo de 10 minutos de duración, más registros asistemáticos. Los censos se realizaron entre las 5 y 11 de la mañana, mientras los registros asistemáticos en todo momento posible durante el día. Se realizaron también capturas con redes de niebla $(8-12$ por día), las redes (12 m x $2.5 \mathrm{~m}$; malla $36 \mathrm{~mm}$ ) estuvieron abiertas entre las 6:00 a 16:00 horas. Además se realizaron de una a dos evaluaciones nocturnas por localidad, recorriéndose en cada ocasión al menos $2 \mathrm{~km}$ desde las 18:40 a las 21:00 horas; y empleando reproducciones de cantos de aves nocturnas con potencial presencia en el Santuario. Para el registro e identificación de las especies se empleó un binocular de 10x40 mm, un reproductor de audio digital Ipod y la guía de identificación de las aves de Perú (Schulenberg et al. 2010). También incluimos las especies de aves registradas de una evaluación con cámarastrampa, funcionando en promedio 45 cámaras-trampa desde agosto 2014 a abril 2015 (esfuerzo de muestreo 7101 días cámara); las cuales abarcaron un mayor área de evaluación que los transectos de los censos (ver mapa en Figura 1).

Sobre el listado.- Para la elaboración del listado de especies registradas dentro del Santuario, se incluyeron los registros de las evaluaciones previas (Amanzo et al. 2003, Barrio 2006, Ze- 


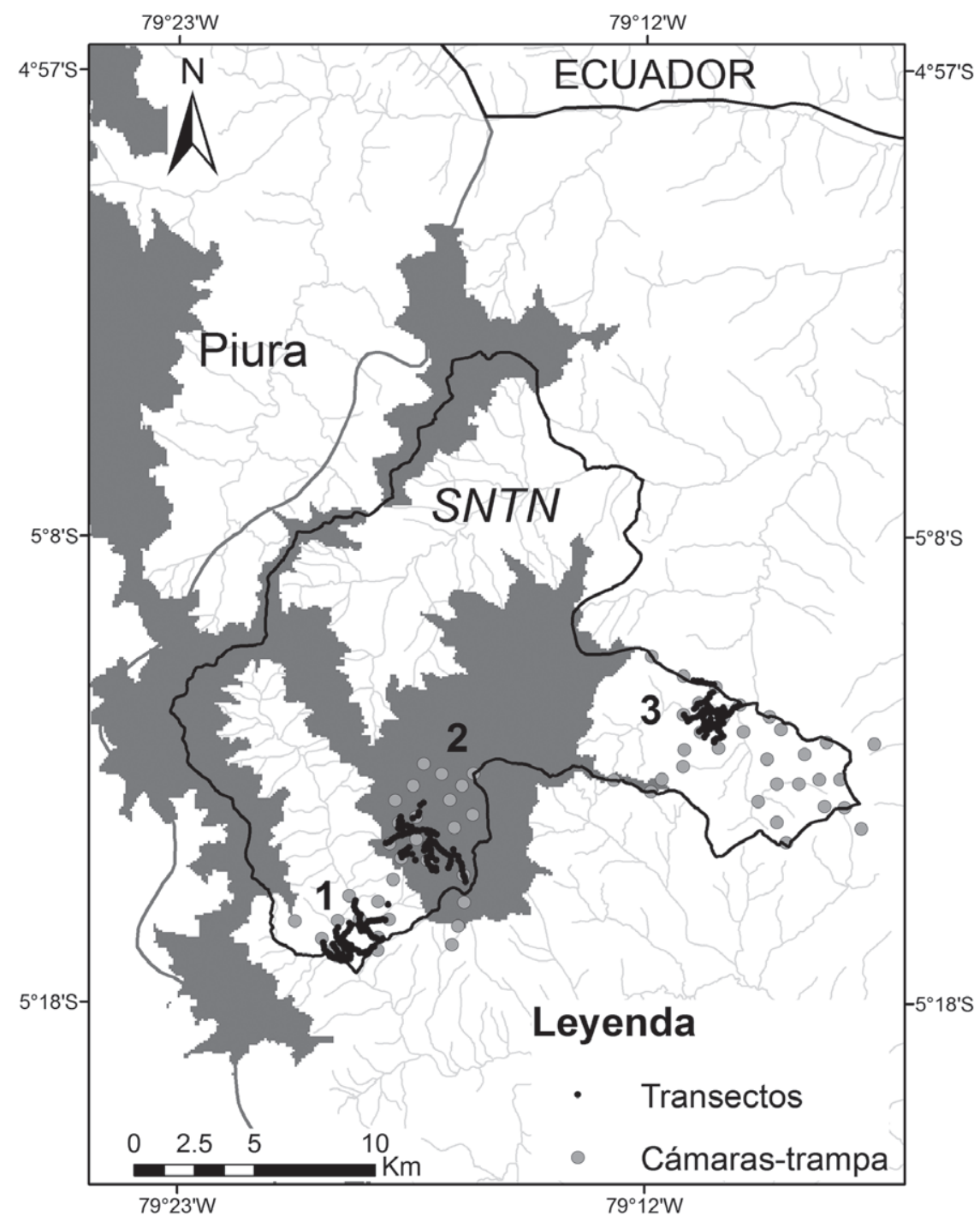

Figura 1. Localidades de evaluación, Santuario Nacional Tabaconas Namballe (SNTN): (1) Chichilapa, (2) Páramos, (3) El Sauce. Sombreado en gris áreas por encima de $3000 \mathrm{msnm}$.

ballos 2010), excluyendo registros no concluyentes (entrevistas, posibles divagantes, no identificadas [“'sp."]). Para la abundancia relativa de las especies del listado, se agruparon en cuatro categorías según su frecuencia de registro como: Común $(\mathrm{C})$, especies registradas todos los días; Casi Común (CC), especies registradas casi todos los días; Poco Común (PC), especies registradas luego de unos días de evaluación; Raras (R), especies registradas una sola vez durante toda la evaluación. Además se incluyen como raras las especies no registradas en la presente evaluación pero si registradas en evaluaciones pasadas.

Se indica el tipo de evidencia o registro según cada evaluación del Santuario: la presente evaluación cuenta con fotos y grabaciones dispuestos en Macaulay Library de Cornell Laboratory of Ornithology (http://macaulaylibrary.org/); la de Zeballos (2010) cuenta con colectas científicas depositadas en el Museo de Historia Natural de la Universidad Nacional de San Agustín en Arequipa; y la de Amanzo et al. (2003) cuenta con colectas científicas depositadas en el Museo de Historia Natural de la Universidad Nacional Mayor de San Marcos en Lima. El estado de conservación es según Birdlife International (2017c), la legislación peruana (DS Nº04-2014-MINAGRI) y los apéndices de la Convención sobre el Comercio Internacional de Especies Amenazadas de Fauna y Flora Silvestres (CITES). El grado de endemismo es según Birdlife International (2017c), para especies endémicas de distribución restringida $\left(<50000 \mathrm{~km}^{2}\right)$; según Devenish et al. (2009) para especies indicadoras de áreas de endemismo (EBA); y Stotz et al. (1996) para endémicos a regiones zoogeográficas (BIOMAS); considerando actualizaciones taxonómicas y de distribución de las especies. La clasificación taxonómica y nombres de las especies siguen a Plenge (2017), acorde al Comité de Clasificación de América del sur (SACC) de la Unión de Ornitólogos Americanos.

\section{Resultados}

Diversidad de especies.- Registramos 197 (40 familias) y 153 (39 familias) especies en época seca y de lluvia respectivamente, con un total de 226 especies y 42 familias (Anexo 1). De las 208 especies de las evaluaciones previas, registramos 153 (73.56\%), 
principalmente casi todas las especies de interés de conservación, contando la mayoría con evidencia fotográfica. Mientras que de las no registradas (55 especies), 20 cuentan con colectas, 6 fueron registradas en dos de las tres evaluaciones previas y 29 solo en una; no obstante la mayoría de ellas también fueron registradas en evaluaciones en localidades aledańas (ver Introducción). Combinando nuestros resultados y los de las cámaras trampa con los de estudios previos, reportamos un total de 290 especies y 46 familias de aves para el Santuario (Anexo 1). Las familias más diversas son cuatro, que en conjunto comprenden el $47.59 \%$ del total de especies, estas son Thraupidae con 48 especies (16.55\%), Tyrannidae con 39 (13.45\%), Trochilidae con 30 (10.34\%) y Furnariidae con 21 (7.24\%). Las especies de interés de conservación están conformadas por: 26 endémicos al bioma de los Andes del Norte (NAN), 7 endémicos de distribución restringida (RR), 8 endémicos pertenecientes a EBAs $(3 \mathrm{al}$ EBA 043, 2 al EBA 044, 3 al EBA 046), 18 entre amenazadas y casi amenazadas de extinción global (9 VU, 9 NT), 9 entre amenazadas y casi amenazadas de extinción en territorio nacional (5 VU, 4 NT) y 51 especies protegidas por la CITES.

Nuevos registros.- Este trabajo reporta 82 nuevos registros de especies para el Santuario, 7 de los cuales provienen de las cámaras trampa. De estos destacan 14 especies, entre endémicos andinos, amenazados de extinción, con expansión de su rango de distribución, y uno hipotético a Perú.

- Gray Tinamou Tinamus tao (Tinamidae) (Fig. 2a). Es un nuevo registro para la región Cajamarca y es el más alto de su distribución altitudinal global, con el cual se extiende de 1900 a 2634 m. En el Perú su distribución se conoce a lo largo de los bosques húmedos de la vertiente oriental hasta los $1400 \mathrm{~m}$; en el noroeste llega hasta el centro y norte de la región Amazonas hasta la frontera con la Región Cajamarca. El presente registro se encuentra más cercano a la frontera con la región Piura que con Amazonas. La especie probablemente es rara en el Santuario, siendo registrada únicamente por las cámaras trampa. Los registros corresponden a bosques montanos en Chichilapa (5¹5'44.31"S, 79¹8'0.45"W, $2634 \mathrm{~m}$; 5¹6'34.23"S, $79^{\circ} 19^{\prime} 16.40 " \mathrm{~W}, 2306 \mathrm{~m}$; 5¹6'46.06"S, 79 $18^{\prime} 58.64 " \mathrm{~W}$, $2052 \mathrm{~m})$ y El Sauce $\left(5^{\circ} 11^{\prime} 49.90^{\prime \prime S}, 79^{\circ} 8^{\prime} 57.74^{\prime \prime W}, 1852\right.$ m; 5¹2'40.57"S, 79¹1'9.90"W, $2577 \mathrm{~m})$.

- Black-billed Mountain-Toucan Andigena nigrirostris (Ramphastidae). Un individuo fue fotografiado en un área circundante a bosques en recuperación; registrado en época húmeda el 14 de marzo de 2015 a las 9:45 am, en la parte sur del Santuario, en la Estación Biológica Chichilapa $\left(05^{\circ} 16.14\right.$ 'S, $\left.79^{\circ} 18.42^{\prime} \mathrm{W},-2200 \mathrm{~m}\right)$. La especie es endémica a los Andes del Norte con distribución considerada hipotética al Perú, aunque existen registros de su distribución en el país recientemente publicados (ver Salazar et al. 2017).

- Olive-chested Flycatcher Myiophobus cryptoxanthus (Tyrannidae) (Fig. 2b). En Perú solo se le conoce en Amazonas y San Martín, hasta los $1750 \mathrm{~m}$; probablemente la especie también se distribuye en la región Cajamarca, la cual cuenta con registros no publicados. Así existen dos grabaciones (ML202983 y ML202986) realizadas por Daniel Lane el 13 y 14 de agosto de 1998, en el caserío Villa Rica (distrito de San José de Lourdes, provincia de San Ignacio), dispuestas en el portal www.macaulaylibrary.org del Laboratorio de Ornitología de la Universidad de Cornell. Nosotros lo registramos en época seca y húmeda dentro del Santuario, en El Sauce a 1870 m (distrito Namballe, provincia de San Ignacio), el 15 de abril de 2015 en época húmeda, capturamos y fotografiamos un individuo. Nuestro registro es el más occidental de su distribución global y probablemente permita confirmar la distribución de la especie en la región Cajamarca. La especie es indicadora del EBA Ecuador-Perú East Andes (EBA 044) y antes era considerada endémica de distribución restringida (Statterfield et al. 1998), no obstante su área de distribución actual alcanza los $147000 \mathrm{~km}^{2}$.

- Masked Mountain-Tanager Buthraupis wetmorei (Thraupidae) (Fig. 2c). Se observó y fotografió por única vez un individuo ubicado entre arbustos ( $5^{\circ} 14^{\prime} 34.25^{\prime \prime S}$, $79^{\circ} 16^{\prime} 35.14^{\prime \prime W)}$ al pie de bosque en el Páramo, en época seca el 4 de octubre de 2014 a las 9:22 am. La especie es sumamente rara, pobremente conocida, con escasos registros en el noroeste del Perú. La especie es endémica al NAN y al EBA 043 (Central Andean páramo). Su población global es Vulnerable de Extinción (VU, IUCN) así como su población en el Perú (VU, DS Nº04-2014-MINAGRI).

- Ruddy Pigeon Patagioenas subvinacea (Columbidae). Fue registrada casi todos los días auditivamente en los transectos de evaluación de El Sauce, normalmente a los 2000 m de altitud. No obstante, registramos un incremento en su rango de distribución altitudinal conocida para Perú de 1900 a 2340 m; globalmente puede alcanzar los $2800 \mathrm{~m}$. La especie es Vulnerable de Extinción Global (VU, IUCN).

- Giant Cowbird Molothrus oryzivorus (Icteridae) (Fig. 2d). Fue registrada en potreros en El Sauce, en época seca y húmeda, siendo un individuo fotografiado el 20 de octubre de 2014. Con el presente registro se incrementa su rango de distribución altitudinal conocida para el Perú (Schulenberg et al. 2010) de 1200 a 1872 m y se confirma su distribución en la región Cajamarca. Aunque existen registros no publicados en la región dispuestos en Ebird, pero de altitudes inferiores a $1200 \mathrm{~m}$. En el Perú la especie se distribuye en toda la selva baja, principalmente bajo los $900 \mathrm{~m}$; globalmente se distribuye hasta los $2000 \mathrm{~m}$.

- Wedge-tailed Grass-Finch Emberizoides herbicola (Thraupidae). Fue registrada por única vez el 18 de octubre de 2014 en época seca, en inmediaciones de un potrero (511'24.27"S, 79²10'23.27"W, 1825 m) en El Sauce. Un individuo el cual no se pudo fotografiar fue observado en el matorral de un parche de bosque secundario, ubicado entre un potrero y una quebrada de agua permanente. El presente registro es el más alto de su distribución altitudinal en el Perú, el cual solo se le conoce hasta los $1450 \mathrm{~m}$; globalmente la especie alcanza hasta los $1900 \mathrm{~m}$. En el Perú se conocen solo tres localidades donde se distribuye la especie: en las Pampas del Heath, valle del río Mayo y Valle del Marañón. Existen grabaciones documentadas no publicadas en Ucayali y Yanacocha, disponibles en Macaulay Library (ML 138712, ML 138714, ML43868121) y en Ebird.

- Palm Tanager Thraupis palmarum (Thraupidae). Fue registrada en época seca y húmeda en las localidades Chichilapa y El Sauce; siendo fotografiado un individuo el 22 de oc- 

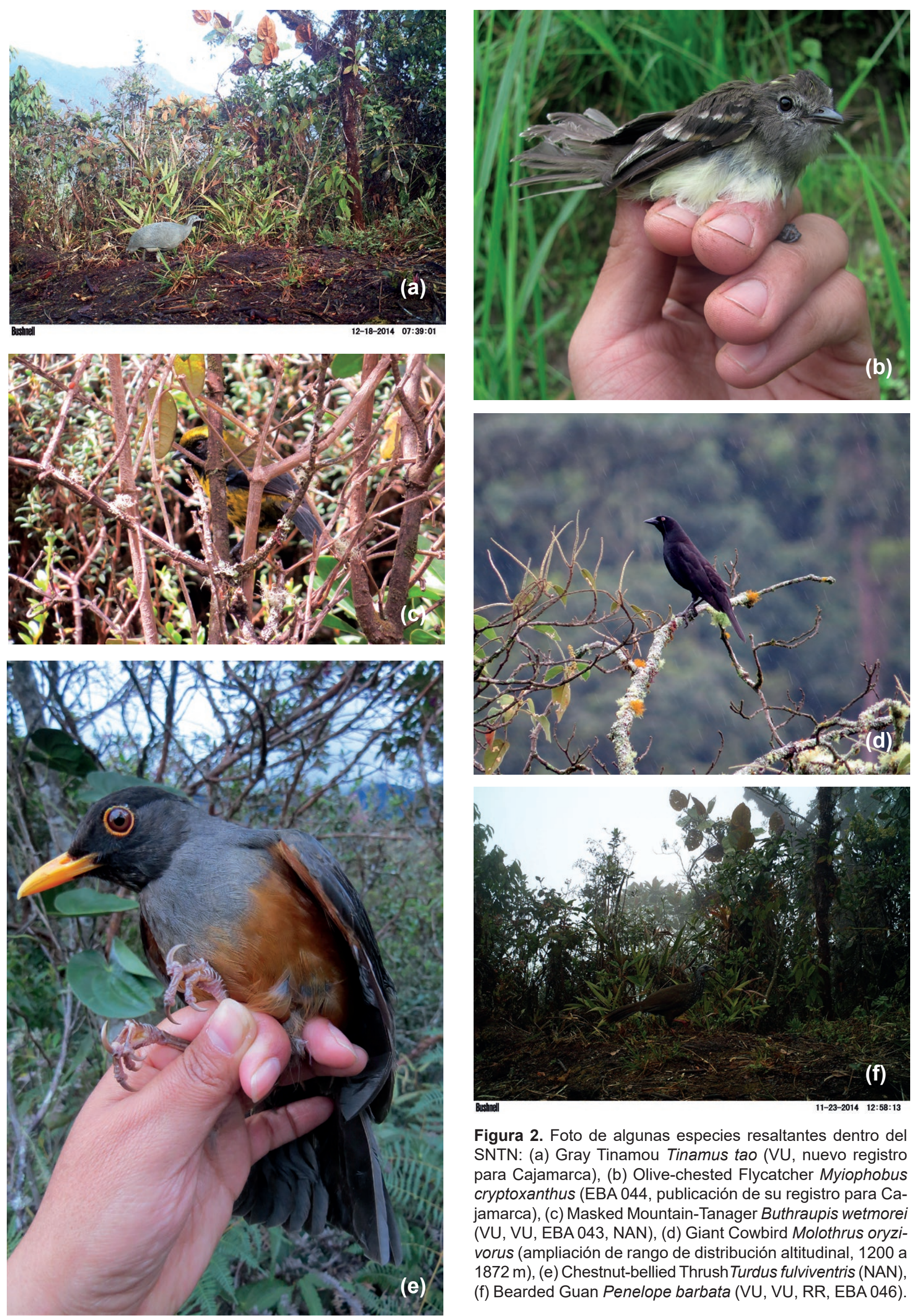

Figura 2. Foto de algunas especies resaltantes dentro del SNTN: (a) Gray Tinamou Tinamus tao (VU, nuevo registro para Cajamarca), (b) Olive-chested Flycatcher Myiophobus cryptoxanthus (EBA 044, publicación de su registro para Cajamarca), (c) Masked Mountain-Tanager Buthraupis wetmorei (VU, VU, EBA 043, NAN), (d) Giant Cowbird Molothrus oryzivorus (ampliación de rango de distribución altitudinal, 1200 a $1872 \mathrm{~m}$ ), (e) Chestnut-bellied Thrush Turdus fulviventris (NAN), (f) Bearded Guan Penelope barbata (VU, VU, RR, EBA 046). 
tubre de 2014 en borde de bosque en El Sauce. Su registro en la localidad Chichilapa (516 $\left.49.38^{\prime \prime S}, 79^{\circ} 18^{\prime} 10.96^{\prime \prime W}\right)$ significa un incremento en su distribución altitudinal conocida para Perú de 1600 a 2128 m; globalmente la especie puede llegar hasta los $2600 \mathrm{~m}$.

- Canada Warbler Cardellina canadensis (Parulidae). Es una especie emigrante boreal registrada visualmente y por única vez, en época seca el 17 de octubre de 2014 en El Sauce $\left(5^{\circ} 11^{\prime} 43.59^{\prime \prime S}, 79^{\circ} 10^{\prime} 28.44^{\prime \prime W}, 2100 \mathrm{~m}\right)$ a las 8:15 am. Este registro supera en $500 \mathrm{~m}$ el límite de distribución altitudinal conocida para Perú. La especie se encuentra en Perú entre los meses de setiembre y abril, siendo raro en el noroeste, probablemente este registro en el Santuario se trate de un individuo divagante.

Los otros nuevos registros destacables son: el White-bellied Antpitta Grallaria hypoleuca y el Chestnut-bellied Thrush Turdus fulviventris (Fig. 2e), ambos con registros fotográficos endémicos del NAN; Rufous-breasted Flycatcher Leptopogon rufipectus (NAN); y los globalmente Casi Amenazados de Extinción Scarlet-fronted Parakeet Psittacara wagleri y Olive-sided Flycatcher Contopus cooperi un migratorio boreal, este último con registro fotográfico.

Otras especies destacables ya registradas en evaluaciones previas son:

- Bearded Guan Penelope barbata (Cracidae) (Fig. 2f). Especie rara, registrada principalmente por las cámaras trampa en Chichilapa (51 $15^{\prime} 44.31^{\prime \prime S}, 79^{\circ} 18^{\prime} 0.45^{\prime \prime W ;} 5^{\circ} 16^{\prime} 34.23^{\prime \prime S}$, $79^{\circ} 19^{\prime} 16.40^{\prime \prime W} 5^{\circ} 16^{\prime} 29.39^{\prime \prime S}, 79^{\circ} 18^{\prime} 45.47^{\prime \prime W) ~ y ~ E l ~ S a u c e ~}$ $\left(5^{\circ} 10^{\prime} 28.79^{\prime \prime S}, 79^{\circ} 11^{\prime} 27.32^{\prime \prime W}\right)$. Se cuenta con grabación de su comportamiento reproductivo, incluyendo la cópula de una pareja, en la zona de amortiguamiento del Santuario. Se cuenta con grabación de su comportamiento reproductivo, incluyendo la cópula de una pareja, cerca de la zona de amortiguamiento del Santuario. Registrado en El Sauce (510'28.79"S, 79¹1'27.32"W, $2608 \mathrm{~m}$ ) el 20 de diciembre de 2014 entre las 6:51 y 7:04 am. Su distribución global es limitada $\left(-16000 \mathrm{~km}^{2}\right)$, es endémico: RR, NAN y al EBA 046 (Southern Central Andes); su estado de conservación global es de Preocupación Menor, pero en el Perú se encuentra Vulnerable de Extinción.

- Wattled Guan Aburria aburri (Cracidae). Especie casi común en El Sauce y Chichilapa; más fácil observar y escuchar al interior del bosque cerca a las trochas, cuando empieza a oscurecer; con muy poca luz se las puede ver cerca. Su población global se encuentra Casi Amenazada de Extinción, en el Perú son Vulnerables de Extinción.

- Neblina Metaltail Metallura odomae (Trochilidae). Especie común, registrada todos los días en los páramos del Santuario; en las áreas arbustivas se las puede observar y fotografiar. Su distribución global es limitada $\left(13600 \mathrm{~km}^{2}\right)$, es endémico: RR, NAN y al EBA 043 (Central Andean Paramo); su estado de conservación global es de Preocupación Menor, pero en el Perú se encuentra Casi Amenazada de Extinción.

- Red-faced Parrot Hapalopsittaca pyrrhops (Psittacidae). Poco común en los páramos del Santuario. Se les escucha y ve pasar en lo alto, difícil de ver cuando descienden a los bosques de las laderas y de las cimas de los cerros. Su distribución global es limitada $\left(33800 \mathrm{~km}^{2}\right)$, es endémico: RR, NAN y al EBA 046 (Southern Central Andes); su estado de conservación global y en territorio nacional es Vulnerable de Extinción.

- Mouse-colored Thistletail Asthenes griseomurina (Furnariidae). Es una especie común en los páramos del Santuario, se la puede observar y fotografiar en zonas arbustivas del páramo. Su distribución global es limitada $\left(24600 \mathrm{~km}^{2}\right)$, es endémico: RR, NAN y al EBA 043 (Central Andean páramo).

- Andean Teal Anas andium (Anatidae). Es endémico de los Andes del Norte, residente común no abundante en los páramos del Santuario ( - 1-6 individuos por laguna); más común en época seca. El seis de octubre de 2014 (época seca) se observó su comportamiento reproductivo, tres individuos nadando en la laguna La Victoria e interactuando juntos, donde dos de ellos copularon.

\section{Discusión}

La diversidad del Santuario aún dista de ser bien conocida, las evaluaciones realizadas abarcan únicamente su zona sureste, por lo que se esperaría que el número reportado de especies pueda incrementarse. Su zona noroeste no posee evaluaciones biológicas debido a su abrupta topografía con numerosas quebradas, no obstante en ella podrían descubrirse especies nuevas para el mundo, ya que estas especies suelen ser descubiertas en zonas de endemismo pobremente estudiadas (Herzog et al. 2012). Por otra parte, aunque en el Santuario están presentes la mayoría de las especies reportadas en evaluaciones de áreas cercanas, aún quedarían por registrar 71 especies que podrían también estar en el Santuario (53 especies del Cerro Chinguela y 26 de los bosques del Chaupe - Cunía - Chinchiquilla). Sin embargo, más de cien especies podrían sumarse, considerando sus conexiones naturales con otras áreas más al norte como el Parque Nacional de Podocarpus en Ecuador, quien con un área mucho mayor presenta 560 especies (Birdlife International $2017 b)$. Inclusive nuevas especies al país podrían sumarse, así en la primera evaluación del SNTN se registró una nueva especie para el Perú, Anas andium (Amanzo et al. 2003) y en las siguientes evaluaciones se registraron casi todas las especies indicadas (más de 20) como nuevas al país por Parker et al. en 1985. El conocimiento de la fauna ornitológica del Santuario, ayuda a completar los vacíos de información de distribución en esta parte de los Andes del Norte. Así lo demuestran nuestros resultados, entre ampliaciones de distribución altitudinal y un nuevo registro de especie para la región Cajamarca (Tinamus tao). En poco tiempo muchas especies han dejado de ser endémicos de distribución restringida (RR), así el mismo Santuario sin considerar actualizaciones de conocimientos de distribución, tendría al menos 11 especies RR.

Si bien el Santuario presenta un alto número de especies de interés de conservación de los Andes del Norte peruano; destacando entre ellos los endémicos del NAN (alrededor del $50 \%$ ) y las del EBA Páramos de los Andes Centrales (todas las de Perú, 3 especies). Quedan por registrar más especies, entre ellas algunas de las reportadas en el colindante Cerro Chinguela, como los endémicos de distribución restringida Siptornis striaticollis (Spectacled Prickletail), Pipreola lubomirskii (Blackchested Fruiteater), Xenerpestes singularis (Equatorial Graytail) 
y Nephelomyias lintoni (Orange-banded Flycatcher); estos dos últimos junto a Sclerurus albigularis (Gray-throated Leaftosser), Gallinago nobilis (Noble Snipe) y Gallinago imperialis (Imperial Snipe) Casi Amenazados de Extinción global; el Vulnerable de Extinción global Cranioleuca curtata (Ash-browed Spinetail); y el que se encuentra En Peligro de Extinción global Spizaetus isidori (Black-and-chestnut Eagle). Probablemente estas especies estén presentes en la zona noroeste del Santuario, área no evaluada donde es fronterizo con el Cerro Chinguela.

Normalmente las evaluaciones "cortas" (de pocos días) en los bosques montanos húmedos de la Cordillera occidental de los Andes del Norte de Perú; han llegado a registrar entre 130 a 160 especies (Zeballos 2010, Golder Associates Perú S. A. 2005, Amanzo et al. 2003, CDC 1992) y alrededor de 270 en evaluaciones casi completas como el Cerro Chinguela (Parker et al. 1985). Excluyendo las siete especies registradas por las cámaras trampa y considerando actualizaciones taxonómicas, llama la atención que en poco tiempo de evaluación el Santuario (283 especies, 88 días de evaluación en total) presente mayor riqueza que el Cerro Chinguela (268 especies, 380 días). De hecho, Chinguela es reconocida como la más rica y estudiada localidad de la Cordillera Occidental de los Andes del Norte de Perú (CDC 1992). No obstante, aunque ambas áreas cuentan con gradientes altitudinales similares, incluyendo bosques montanos húmedos, páramos y zonas antrópicas; el área del Santuario que es poco más del doble, presenta lugares inexplorados y sus áreas antrópicas se encuentran en regresión; por lo que la posibilidad de registrar más especies es alta. Sin embargo, la protección del Santuario podría explicar mejor su mayor riqueza, al refugiar a muchas especies procedentes de zonas circundantes no protegidas con problemas de deforestación. Como los bosques de Cunia-Chaupe-Chinchiquilla en su lado sureste y el Cerro Chinguela contiguo a su lado noroeste. En términos generales el Santuario está rodeado por áreas intervenidas que se concentran en su lado oriental (INRENA 2007), podría esperarse que muchas especies de estas áreas se hayan refugiado dentro del Santuario.

El Santuario tiene un rol preponderante en la conservación de una muestra representativa de las aves de los Andes del Norte de Perú, al ser la única Área Natural Protegida que la resguarda. Más aún al tratarse del resguardo de un área limitada en el país, de distinguido endemismo, el cual diariamente pierde sus áreas verdes a causa de la colonización, expansión agrícola, ganadería extensiva, minería informal, tala ilegal, entre otras amenazas(Salazar et al. 2017). El trabajo de la Jefatura del Santuario ha sido clave para el mantenimiento de la cobertura de bosques tanto dentro como en la zona de amortiguamiento del Santuario (Valdivia 2010, INRENA 2007). No obstante, el mejoramiento del camino vecinal Alto Ihuamaca - Tamborapa Pueblo, la cual atraviesa su zona de amortiguamiento, conectando varios pueblos como Tamborapa Pueblo, Ihuamaca, San Miguel, Nuevo Lima, Nuevo Paraíso, El Chaupe, Unión, Las Minas, entre otros de su lado este (Resolución Ministerial 848-2014-MTC/01, INRENA 2007), han facilitado el acceso a bosques dentro y fuera del Santuario. Por lo que se requiere urgente de un ordenamiento territorial que contribuya a una coexistencia entre la fauna en general y las actividades productivas que desarrolla la población local.

El Santuario mantiene conexiones naturales con los bosques montanos y páramos de Ecuador y Colombia, la cual se viene favoreciendo en Perú mediante la gestión de creación de Áreas de Conservación Privada (ACP) y Áreas de Conservación Regional (ACR) norandinas. Entre ellas la reciente creación del ACP Bosques Montanos y paramos Chicuate - Chinguelas y las propuestas de creación del ACR Bosques El Chaupe, Cunia y Chinchiquilla y del ACR Bosques Montanos de la Cordillera Real Oriental de Jaén (Resolución Ministerial $N^{\circ}$ 138-2016-MINAM, Gobierno Regional Cajamarca 2016a, b); con el cual se reforzarían las interconexiones con sus bosques y páramos de su lado noroeste, este y sur respectivamente. Contra las actividades antrópicas que generan la pérdida de sus bosques e interconexiones, es fundamental el desarrollo de actividades económicas que sean amigables con la conservación, como el ecoturismo o el aviturismo (Herzog et al. 2012). De hecho, el Santuario puede ser una excelente oportunidad, al ofrecer no solo una gran diversidad y endemismo de aves, sino también una naturaleza única, entre paisajes, bosques húmedos, lagunas errebiatas, páramos en buen estado de conservación, los últimos probablemente que tienen esa condición en el país.

\section{Agradecimientos}

A World Wildlife Fund - Perú por financiar el trabajo de campo. Al jefe del Santuario Ing. Douglas Cotrina por facilitar el trabajo de campo. Un especial agradecimiento a Cristina Campos a los guardaparques Jesús Aponte, Evelio Lozada y al apoyo local el señor Javier Tocto, por su incondicional y valiosa ayuda en el trabajo de campo en la época seca. También agradecer a la familia Correa, al guardaparque Alexander Campos y al joven Yordy Cruz por su valiosa ayuda en campo. A Hiromi Yagui, Vania Tejeda, Sofía Valdivia y Karina Huamán por la ayuda con las fotos de las cámaras trampa. A Daniel Lane por su gentil ayuda en la identificación de algunas especies. A Elena Vivar, Alfredo Begazo y Thomas Schulenberg por la revisión y sugerencias del manuscrito. A Manuel Plenge por la información bibliográfica brindada. A todos ellos muchas gracias.

\section{Literatura citada}

Amanzo J., R. Acosta, C. Aguilar, K. Eckhardt, S. Baldeón \& T. Pequeño. 2003. Evaluación biológica rápida del Santuario Nacional Tabaconas Namballe y zonas aledañas. Informe WWF - OPP: QM-91. Lima. 212 pp.

Barrio, J. 2006. Análisis de la comunidad de aves presente en las Lagunas Arrebiatadas y zona de páramo circundante, Santuario Nacional Tabaconas Namballe. Lima: Centro de Datos para la Conservación, Universidad Nacional Agraria La Molina.

BirdLife International. 2017a. Important Bird Areas factsheet: Santuario Nacional Tabaconas-Namballe. Downloaded from http://www.birdlife.org on 16/02/2017.

BirdLife International. 207b. Important Bird Areas factsheet: Parque Nacional Podocarpus. Downloaded from http://www. birdlife.org on 16/02/2017.

BirdLife International. 2017c. BirdLife's Global Species Programme. http://www.birdlife.org/datazone/species.

Centro de Datos para la Conservación (CDC). 1992. Evaluación de los bosques de protección "Montañas de Manta" (Jaén) y "El Chaupe-Cunía-Chinchiquilla-El Tunal" (San Ignacio). Departamento de Cajamarca. Facultad de Ciencias Forestales. Universidad Agraria La Molina.

Devenish C., F. Díaz, R. Clay, I. Davidson \& I. Yépez, EDS. 2009. Important Bird Areas Americas - Priority sites for biodiversity conservation. Quito, Ecuador: BirdLife International (BirdLife Conservation Series No. 16).

DS N004-2014-MINAGRI. Actualización de la lista de clasificación y categorización de las especies amenazadas de fauna silvestre legalmente protegidas. Ministerio de Agricultura 08 de abril 
de 2014. El Peruano Normas Legales: 520497-520504.

Gobierno Regional Cajamarca. 2016a. NOTA DE PRENSA No 005 - 2016-GR.CAJ/RENAMA, Se conformará Comité de Gestión para Bosques el Chaupe, Cunia y Chinchiquilla. Fecha de publicación 17-02-2016.

Gobierno Regional Cajamarca. 2016b. NOTA DE PRENSA No 008 - 2016-GR.CAJ/RENAMA, Se conformó Comité de Apoyo de propuesta de ACR Bosques Montanos de la Cordillera Real Oriental de Jaén. Fecha de publicación 17-02-2016.

Golder Associates Perú S. A. 2005. Informe Línea Base ornitológica Proyecto Río Blanco.

Herzog S., R. Martínez, P. Jørgensen \& H. Tiessen (eds.). 2012. Cambio Climático y Biodiversidad en los Andes Tropicales. Instituto Interamericano para la Investigación del Cambio Global (IAI), São José dos Campos, y Comité Científico sobre Problemas del Medio Ambiente (SCOPE), Paris. Pp. 235-253.

Holdridge L.R. 1967. Life zone ecology. Tropical Science Center, San José, Costa Rica. 216 pp.

INRENA. 2007. Plan Maestro del Santuario Nacional Tabaconas Namballe 2007-2011. Lima.

Parker III, T.A., T.S. Schulenberg, G.R. Graves \& M.J. Braun. 1985. The avifauna of the Huancabamba region, northern Peru. Ornithological Monographs 36: 169-197.

Plenge M.A. 2017. Lista de las aves del Perú. Lima, Perú.

Resolución Ministerial 848-2014-MTC/01. Aprobación del presupuesto institucional de apertura del pliego 036: Ministerio de Transportes y Comunicaciones, correspondiente al año fiscal 2015. Proyecto 2176697: Mejoramiento de camino vecinal Alto Ihumaca - Tamborapa Pueblo, distrito de San Ignacio, província de San Ignacio - Cajamarca. Fecha de publicación: 16-12-2014

Resolución Ministerial N 138-2016-MINAM. Reconocimiento del Área de Conservación Privada Bosques Montanos y Páramos Chicuate - Chinguelas.

Salazar S., J.L. Mena, D.F. Lane \& C.C. Witt. 2017. Estatus y distribución en el Perú del Tucán Andino de Pico Negro Andigena nigrirostris (Waterhouse, 1839). Revista peruana de biología 24(1): 055 - 058 (Abril 2017). doi: http://dx.doi. org/10.15381/rpb.v24i1.13106.

Schulenberg T.S., D.F. Stotz, D.F. Lane, J.P. O’Neill \& T.A. Parker III. 2010. Birds of Peru. Revised and updated edition. Second printing, and first paperback printing, revised and updated. Princeton University Press, Princeton, New Jersey, p. 274.

Statterfield, A., M. Crosby, A. Long y D. Wege. 1998. Endemic Birds Areas of the World. Birdlife Conservation Series. No. 7. $446 \mathrm{pp}$.

Stotz D., J. Fitzpatrick T. Parker III \& D. Moskovits. 1996. Neotropical Birds. Ecology and Conservation. University of Chicago.

Zeballos H. 2010. Inventario Biológico: Mamíferos, aves, anfibios, reptiles, insectos del Santuario Nacional Tabaconas Namballe - SNTN. Informe final.

Valdivia, G. 2010. "Los actores sociales para la conservación”. Pp. 117-122. En: Conociendo el santuario nacional Tabaconas Namballe (Eds. J.L. Mena y G. Valdivia). World Wildlife Fund - Oficina del Programa Perú, Lima. 







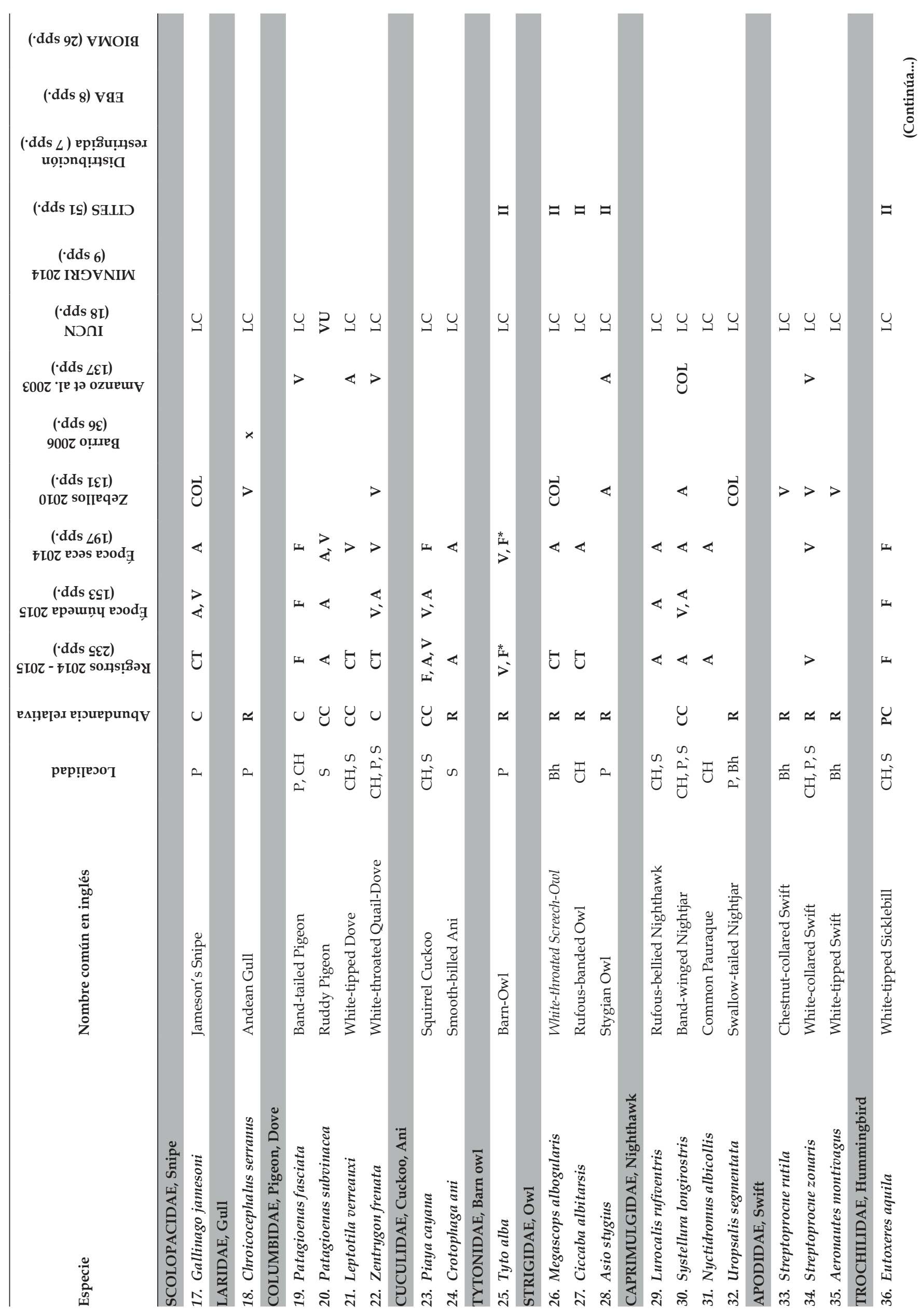




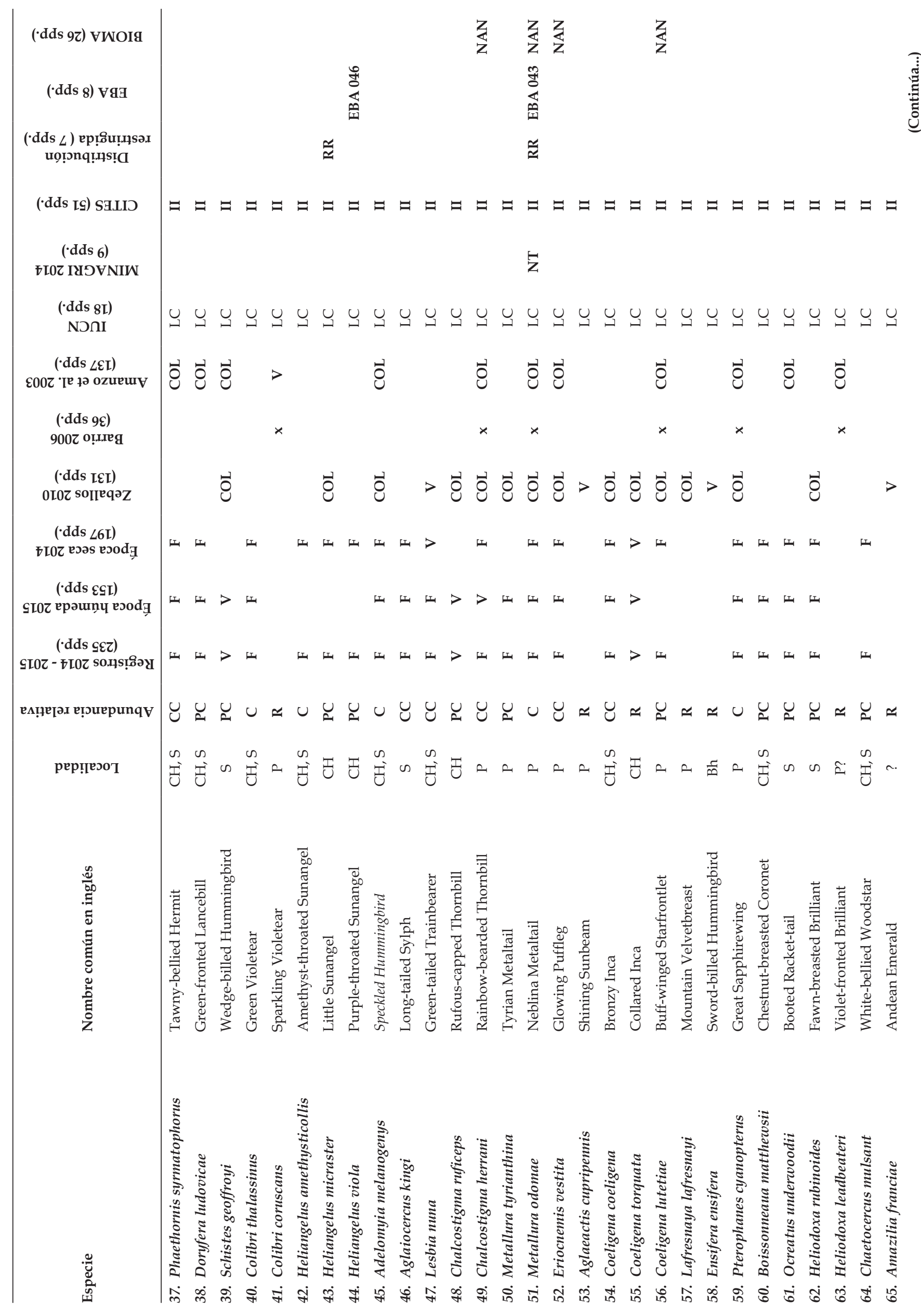




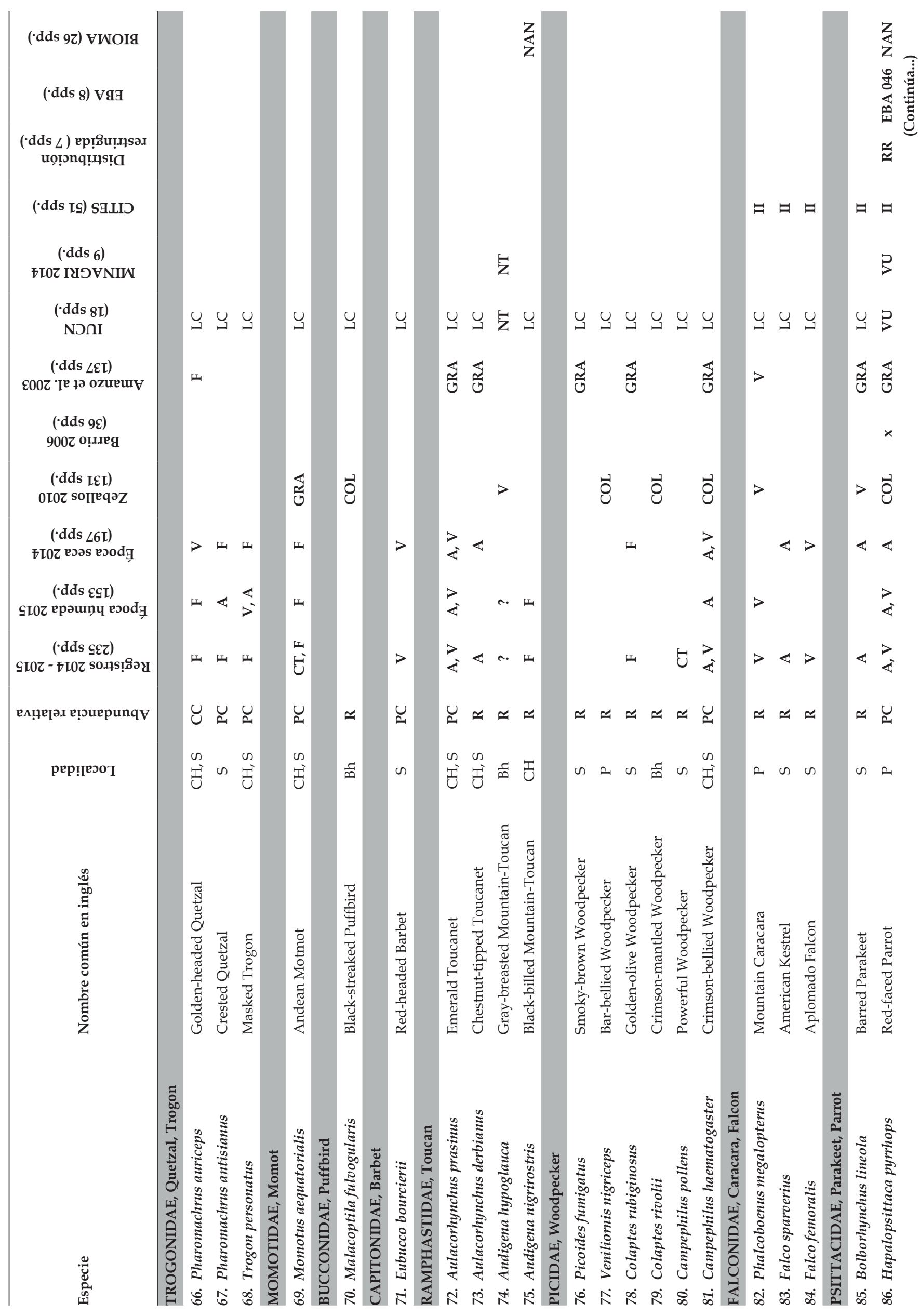




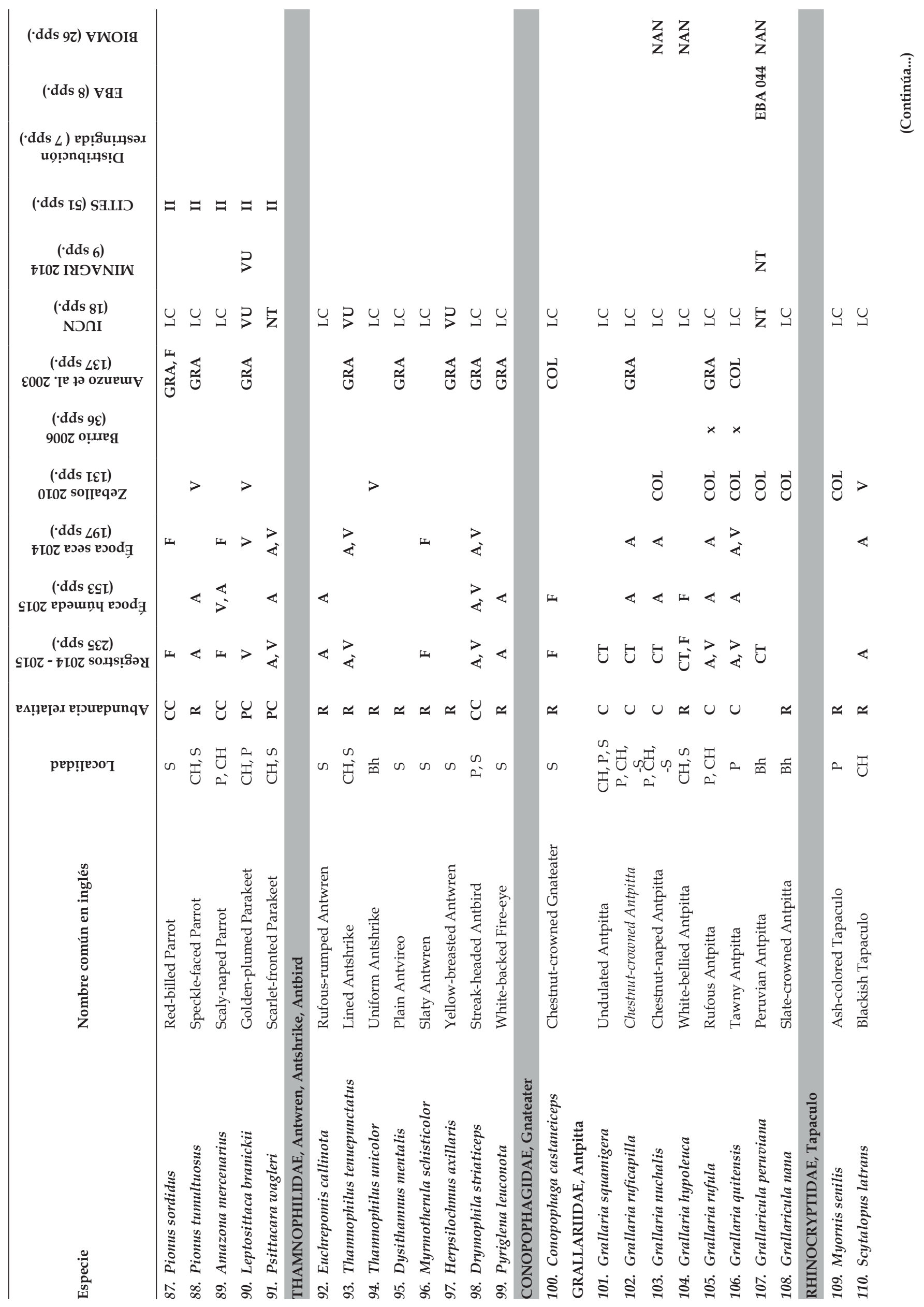




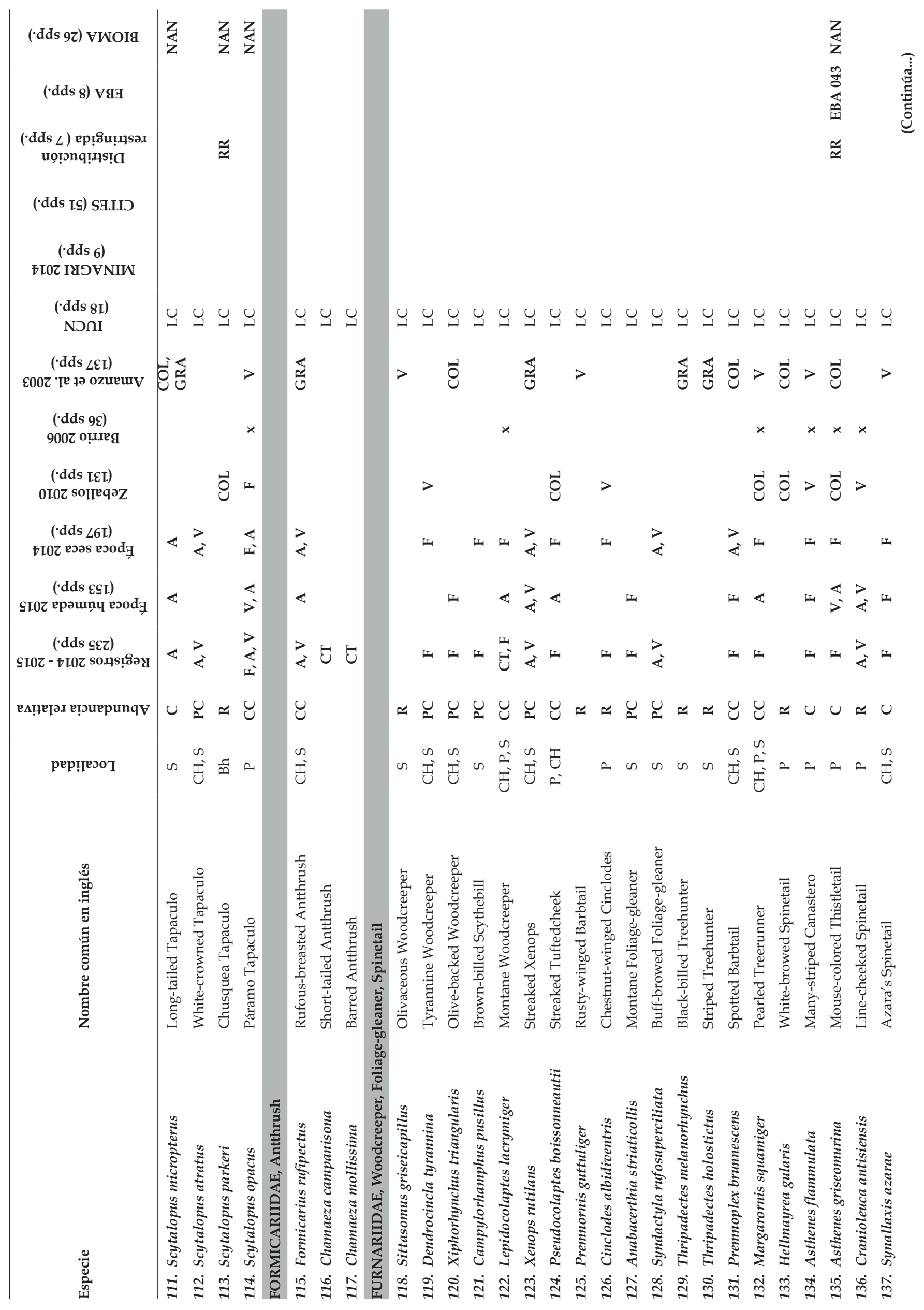




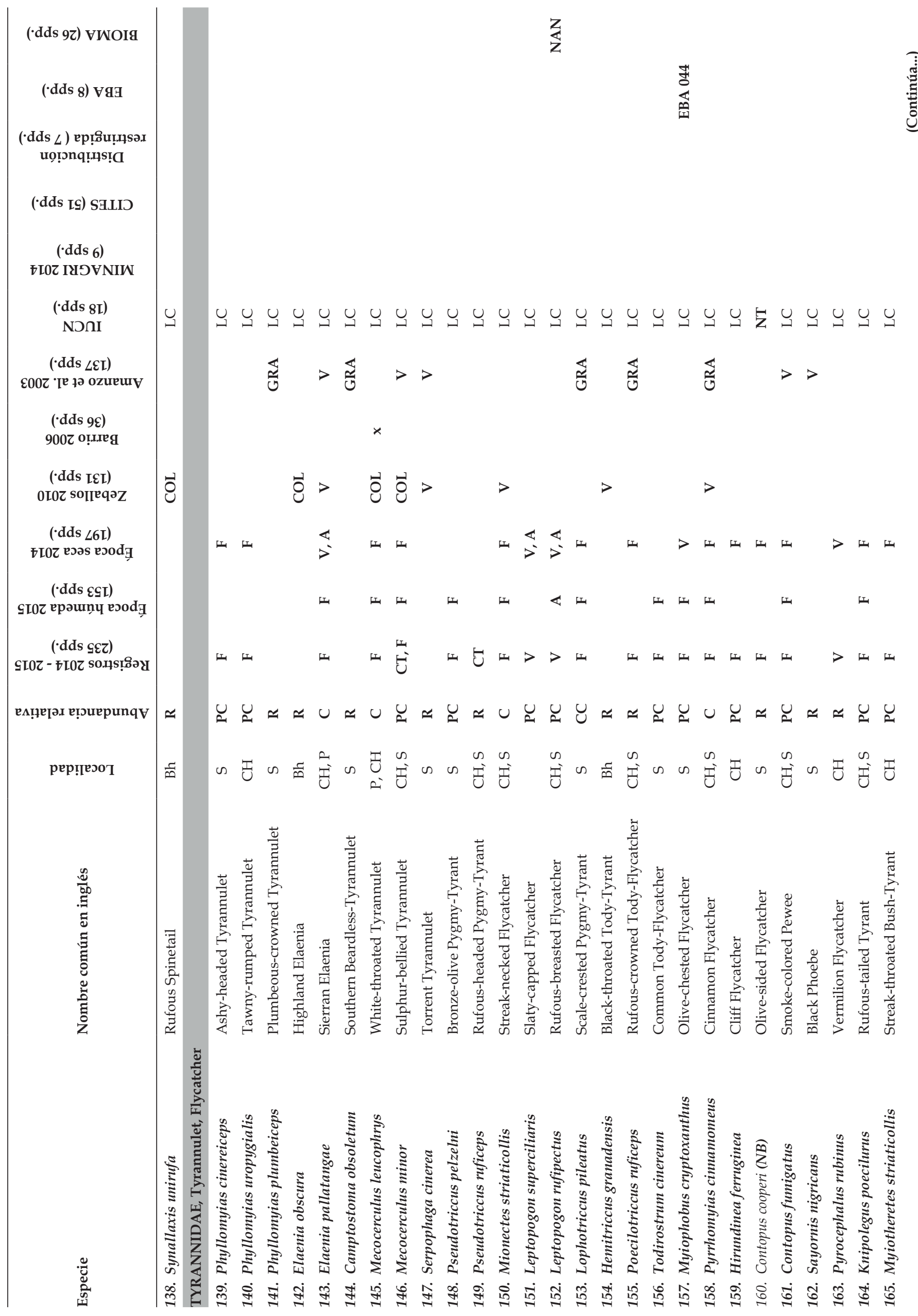




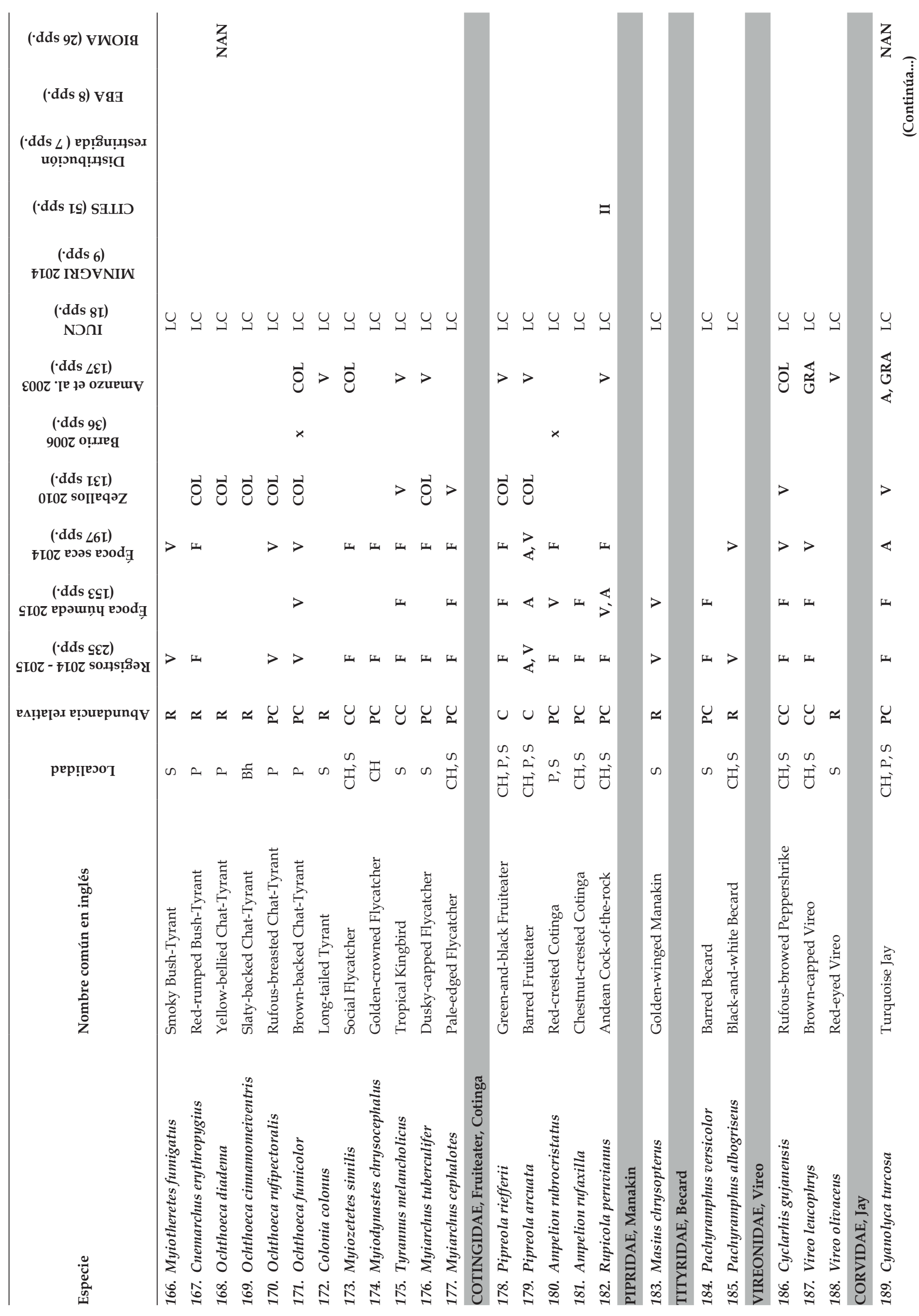




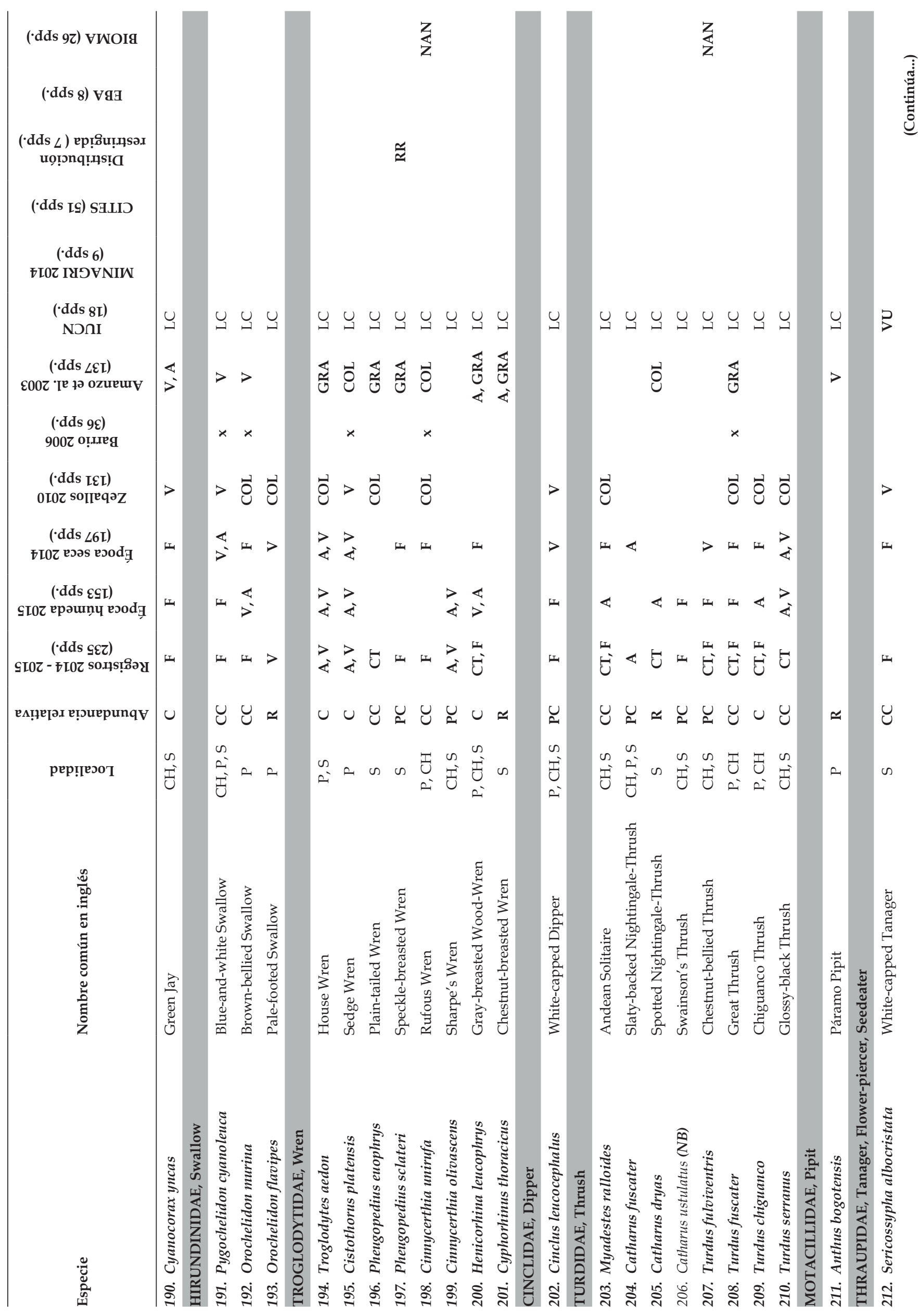




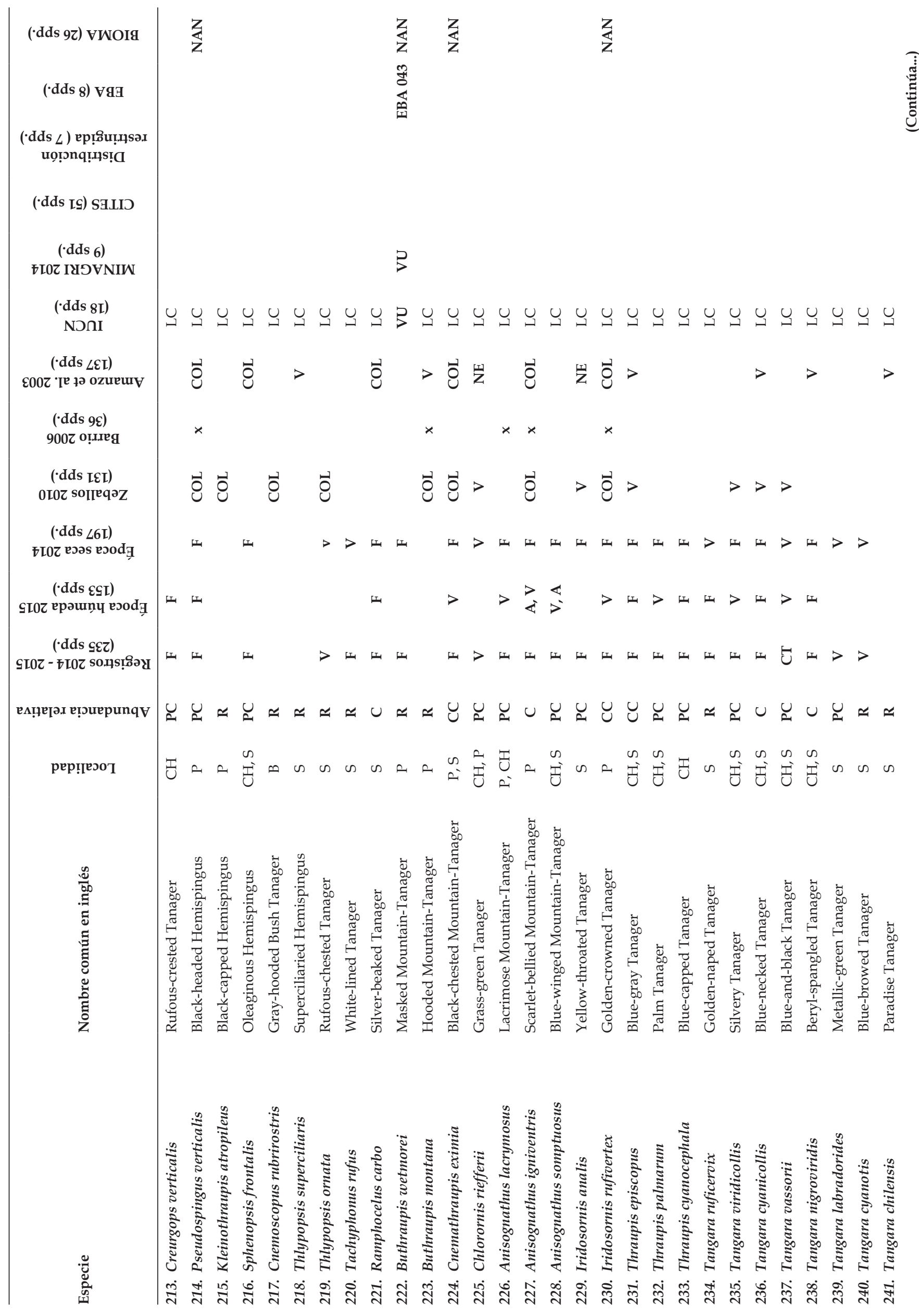




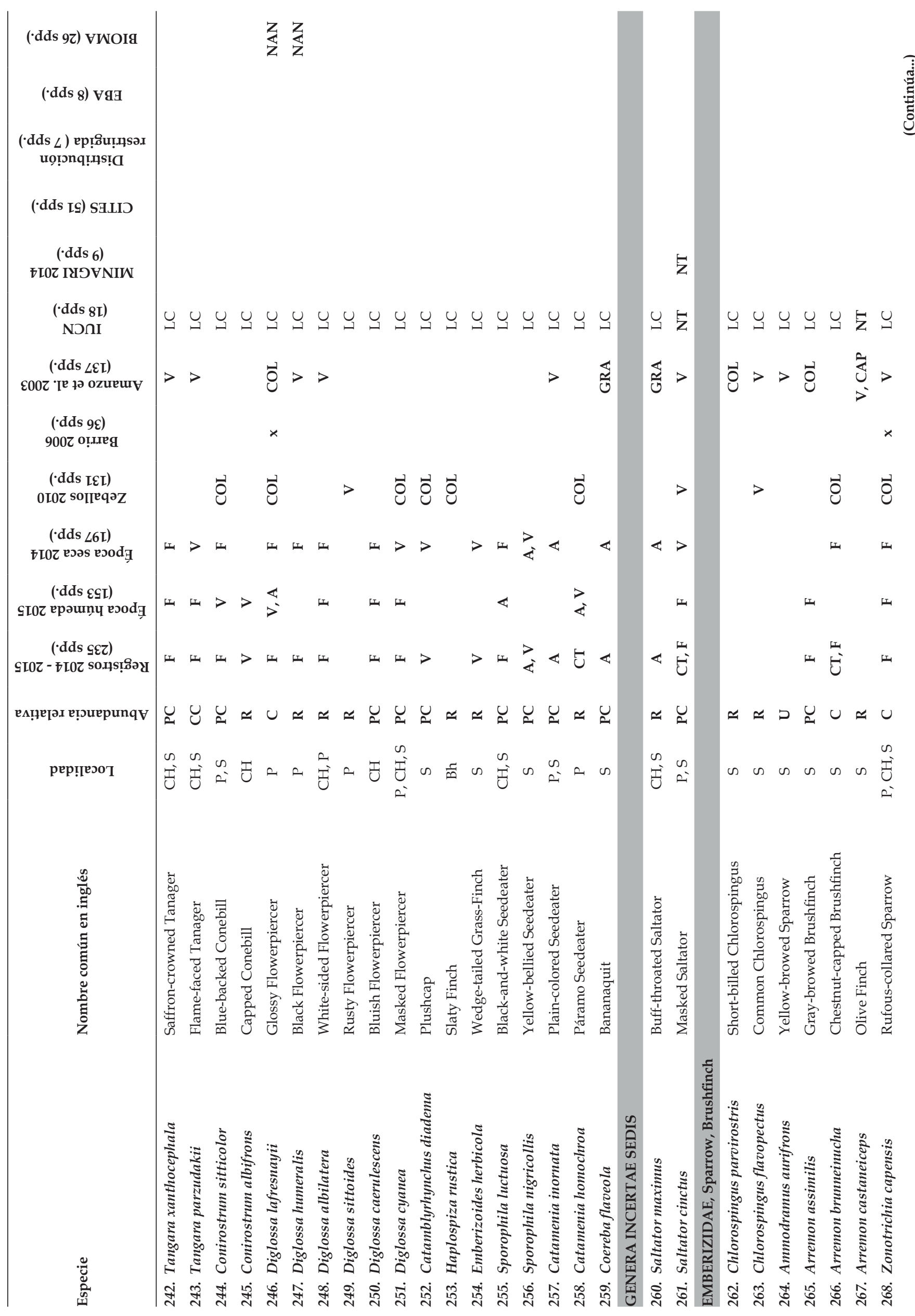




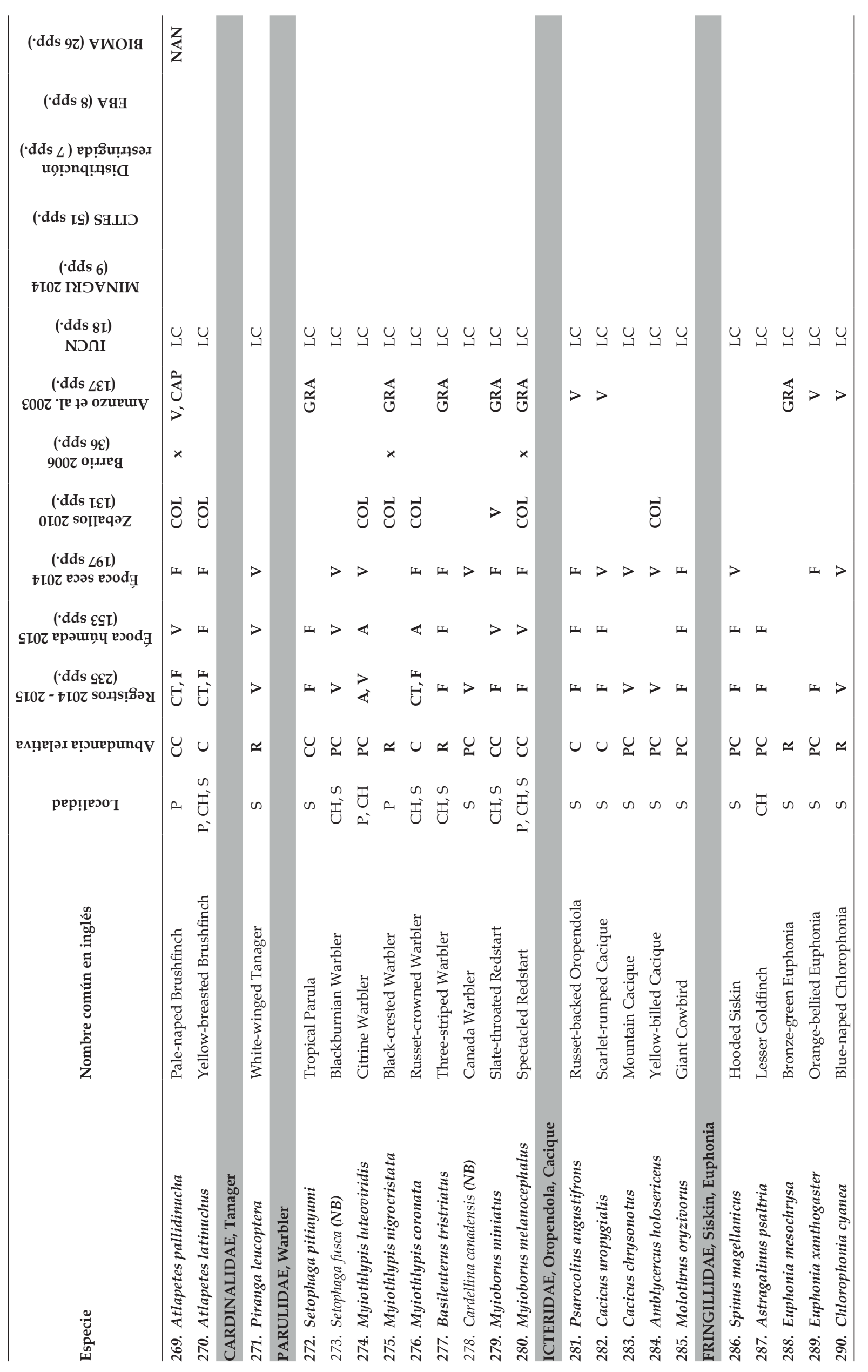

